\title{
Expression of Wnt5a defines the major progenitors of fetal and adult Leydig cells
}

Authors: Herta Ademi ${ }^{1,2}$, Isabelle Stévant ${ }^{1,2}$, Chris M Rands ${ }^{1,2,3}$, Béatrice Conne ${ }^{1}$, Serge $\operatorname{Nef}^{1,2, *}$.

\section{Affiliations:}

${ }^{1}$ Department of Genetic Medicine and Development, University of Geneva, 1211 Geneva, Switzerland;

${ }^{2}$ iGE3, Institute of Genetics and Genomics of Geneva, University of Geneva, 1211 Geneva, Switzerland;

${ }^{3}$ Swiss Institute of Bioinformatics, Geneva, Switzerland;

\section{Lead Contact:}

*Corresponding Author: Serge.Nef@unige.ch 


\section{Summary (149 words)}

Leydig cells (LCs) are the major androgen-producing cells in the testes. They arise from steroidogenic progenitors, whose origins, maintenance and differentiation dynamics remain largely unknown. Here, we identified Wnt5a as a specific marker of steroidogenic progenitors, whose expression begins at around E11.5-E12.5 in interstitial cells of the fetal mouse testis. In vivo lineage tracing indicates that Wnt5aexpressing progenitors are initially present in large numbers in the fetal testis and then progressively decrease as development progresses. We provide evidence that Wnt5a-expressing cells are bona fide progenitors of peritubular myoid cells as well as fetal and adult LCs, contributing to most of the LCs present in the fetal and adult testis. Additionally, we show in the adult testis that Wnt5a expression is restricted to a subset of LCs exhibiting a slow but noticeable clonal expansion, revealing hitherto unappreciated proliferation of fully differentiated LCs as a contribution to the adult LC pool.

Keywords:

Testis, development, Wnt5a, Leydig cells, peritubular myoid cells, lineage tracing, progenitors, single cell transcriptomics, gene editing. 


\section{Introduction}

Leydig cells are the major steroidogenic cells in the testes. They synthetize androgens that are essential for development of the Wolffian duct derivatives, masculinization of secondary sexual characteristics such as male external genitalia and spermatogenesis. In rodents, two distinct populations of LCs have been identified, one arising during the fetal period -henceforth referred to as fetal Leydig cells or FLCs - and the other after puberty referred to as adult Leydig cells, abbreviated ALCs (Chen et al., 2016; Chen et al., 2017; Teerds and Huhtaniemi, 2015).

During the process of male sex determination, Sertoli cells are the first somatic cell type to differentiate at around E11.5 in mice (Albrecht and Eicher, 2001; Gubbay et al., 1990; Hacker et al., 1995; Koopman et al., 1990; Lovell-Badge and Robertson, 1990), and are essential for directing the differentiation of FLCs (Barsoum and Yao, 2006; Habert et al., 2001). The dramatic increase in the number of FLCs between E12.5 and E15.5 occurs through the recruitment and differentiation of Leydig progenitor cells via paracrine factors, rather than by mitotic division of differentiated FLCs (Barsoum et al., 2009; Barsoum and Yao, 2010; Bitgood et al., 1996; Brennan et al., 2003; Byskov, 1986; Kerr and Knell, 1988; Migrenne et al., 2001). During the first postnatal days, FLCs involute gradually and are replaced by ALCs, although some may persist in the adult testis (Haider, 2004; Shima et al., 2015; Wen et al., 2016). ALCs are not derived from pre-existing FLCs but, like their fetal counterparts, arise from uncharacterized LC progenitors located in the testicular interstitium (Barsoum et al., 2013; Davidoff et al., 2004; Kilcoyne et al., 2014; Shima et al., 2012).

The origin of FLCs and ALCs has been heavily debated over recent decades, but has not been completely resolved. A synthesis of current models suggests the presence of several types of Leydig progenitors derived from various sources that have the potential to give rise to both FLCs and ALCs. Recent studies using in vivo cell lineage tracing revealed that FLCs and ALCs derive from two fetal sources: (i) gonadal progenitors that originate from the coelomic epithelium and express the markers NR5A1, ARX, PDGFRA and (ii) mesenchymal progenitor cells from the gonad/mesonephric border that migrate into the developing testis and express Nestin and NOTCH1 (DeFalco et al., 2011; Karl and Capel, 1998; Kumar and DeFalco, 2018; Rotgers et al., 2018). In parallel, some studies indicated 
that both FLCs and ALCs develop from the same precursor pool, but that some of these progenitors remain dormant until prepubertal development, at which point they develop into ALCs (Barsoum et al., 2013; Davidoff et al., 2004; Ge et al., 2006; Svingen and Koopman, 2013). Indeed, perturbation of FLC differentiation by constitutive activation of the hedgehog pathway resulted in an increased number of FLCs and a parallel reduction in the number of ALCs later in puberty suggesting a common pre-established pool of progenitors for both FLCs and ALCs in the fetal testis (Barsoum et al., 2013). Finally, recent findings using in vivo lineage tracing revealed that a significant proportion of ALCs originate from dedifferentiated FLCs in mice (Shima et al., 2018).

Considering coelomic epithelium-derived progenitors, we have recently shown by singlecell RNA sequencing (scRNA-seq) that there is initially a unique coelomic epitheliumderived $\mathrm{Nr}_{5} \mathrm{al}^{+}$progenitor cell population at E10.5, contributing to both supporting and steroidogenic lineages in XX and XY gonads (Stevant et al., 2019; Stevant et al., 2018). A subset of these multipotent cells maintain their progenitor state and, by E12.5, undergo gradual transcriptional changes, acquiring a steroidogenic fate by progressively expressing Pdgfra (platelet-derived growth factor receptor alpha) (Brennan et al., 2003; Eliveld et al., 2019; Ge et al., 2006), Arx (aristaless-related homeobox) (Miyabayashi et al., 2013), Nr2f2 (nuclear receptor subfamily 2 group F member 2 or Couptf2) (Kilcoyne et al., 2014; Qin et al., 2008) and Tcf21 (transcription factor 21, or Pod1) (Cui et al., 2004). Whether these fetal steroidogenic progenitors persist during development and into adult life is unclear. Similarly, questions remain unanswered concerning the fate of these progenitors over time and their ability to produce FLCs and ALCs, or both, during development and later in life. Here we used scRNA-seq and inducible cell lineage tracing experiments to address these questions.

\section{Results}

\section{Identification of Wnt5a as a marker of gonadal steroidogenic progenitors}

Using time-series scRNA-seq on $\mathrm{XX}$ and $\mathrm{XY}$ somatic $\mathrm{Nr}^{2} \mathrm{al}^{+}$cells spanning the sex determination process, we identified a single population of multipotent progenitors that give rise to both pre-supporting cells and potential steroidogenic precursor cells (Figure 
1A) (Stevant et al., 2019; Stevant et al., 2018). Further expression analysis of this singlecell data revealed that the Wnt5a gene is specifically enriched in somatic progenitors when they commit to a steroidogenic fate at around E12.5 (Figure 1B-E). We confirmed by RNAscope in situ hybridization (ISH) in mouse fetal testes at E12.5 that Wnt5a mRNA expression is restricted to interstitial cells and exhibits a dorso-ventral gradient consistent with the coelomic epithelial origin of these progenitors (Figure 1F) (Chawengsaksophak et al., 2012). This suggests that Wnt5a could be used as a cell marker to label this population of steroidogenic progenitors and follow their fate and differentiation during the process of testicular development and into adulthood.

\section{Use of the inducible Tet-On system for characterizing the fate of Wnt5a-expressing steroidogenic progenitor cells}

To trace the contribution of the $W n t 5 a^{+}$steroidogenic progenitors in the appearance of LCs in the developing testis and in adults, we employed an inducible Tet-On system. The TetOn system allows non-invasive and efficient activation of a reporter gene by the administration of doxycycline (dox) in drinking water (Perl et al., 2002; Thorel et al., 2010). The use of doxycycline rather than tamoxifen in inducible systems to control Cremediated recombination has a major advantage for the study of reproductive organ development because tamoxifen exposure has been shown to cause adverse effects on the testis and the reproductive endocrine system (Patel et al., 2017). We first generated a Wnt5a:Tet-On3G knock-in line in which the tetracycline-inducible expression system transgene (Tet-On 3G) was inserted into the first coding exon of the Wnt5a gene (see Materials \& Methods and Figure 2A), so that its expression accurately reflects the endogenous expression of Wnt5a. XX and XY heterozygous knock-in Wnt5a:Tet-On3G animals display no phenotype when compared to control animals (Figure S1-S3 and

\section{Supplementary data).}

We then crossed the Wnt5a:Tet-On3G knock-in line with TetO:Cre and R26:tdTomato reporter lines to generate triple transgenic Wnt5a:Tet-On3G;TetO:Cre;R26:tdTomato mice

(Figure 2A). These mice enable dox-inducible, irreversible expression of tdTomato in Wnt5a-expressing cells. As expected, Tomato ${ }^{+}$cells were not detected in both Wnt5a:Tet- 
On3G;TetO:Cre;R26:tdTomato without dox treatment and in those of control genotypes (i.e. Wnt5a:Tet-On3G;R26:tdTomato and TetO:Cre;R26:tdTomato) with dox induction.

To confirm the high labeling efficiency of our Wnt5a cell lineage tracing system, we first verified by quantitative RT-PCR (qRT-PCR) that Wnt5a transcripts were specifically expressed in Tomato ${ }^{+}$testicular cells. We chose this approach because no antibody worked effectively to detect WNT5A by immunofluorescence. For this purpose, Wnt5a:TetOn3G;TetO:Cre;R26:tdTomato embryos were induced with dox at E11.5 for 24 hours. At E12.5 testes were dissected and Tomato $^{+}$and Tomato $^{-}$populations were sorted by fluorescence-activated cell sorting (FACS). We found that Wnt5a transcripts were highly enriched in the pool of purified Tomato ${ }^{+}$cells, confirming that Tomato labelling is efficient and specific to cells expressing Wnt5a (Figure 2B). Similar results were obtained when Tomato labelling was induced by dox at E15.5 for 24 hours or at post-natal day (P) 0 for five days (Figure 2C\&D). In addition, we performed in situ hybridization for Wnt5a transcripts and immunofluorescence (IF) for Tomato on 24-hour dox-induced E12.5 testis sections. In agreement with the qRT-PCR data (Figure 2B), the double labelling revealed strong Wnt5a-Tomato co-labelling and similar interstitial cell-restricted expression profiles with a dorso-ventral gradient (Figure 2E-J). All together, these results demonstrate that our Wnt5a:Tet-On3G;TetO:Cre;R26:tdTomato mouse model can be used for a specific and efficient dox-inducible, irreversible labelling of $W n t 5 a^{+}$cells.

\section{$W_{n t 5} a^{+}$cells dox-induced at E11.5-E12.5 are steroidogenic progenitors contributing to the majority of FLCs and ALCs}

In order to study in vivo the presence of $W n t 5 a^{+}$steroidogenic progenitors and their fate during testicular development from fetal age to adulthood, we performed a lineage tracing of the cells expressing Wnt5a in the fetal testis. Based on our knowledge of Wnt5a expression during early testis differentiation, E11.5 Wnt5a:TetOn3G;TetO:Cre;R26:tdTomato embryos were dox-induced for a short period of 24 hours and testes were analyzed by immunofluorescence at E12.5, E13.5, P0, P10 and P60 (Figure 3). Whole-organ fluorescence analysis reveals strong Tomato signal in the interstitial compartment from E12.5 onwards (Figure 3A-E). At E12.5, we found that most Tomato ${ }^{+}$ cells co-expressed NR2F2 (also known as COUP-TFII) and/or ARX, indicating that 
Wnt5a-expressing cells display the characteristics of steroidogenic progenitors (Figure 3F,

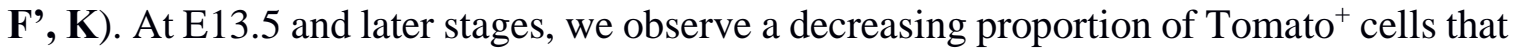
co-express NR2F2 and ARX over time (Figure 3 G-J, G'-J', L-O). It should be noted, however, that even in the adult testis (P60) a few Tomato and ARX co-expressing cells were still present, suggesting the persistence of a small pool of steroidogenic progenitors in adulthood (Figure 30). To determine whether the $W n t 5 a^{+}$steroidogenic progenitor cells also have a perivascular origin, we co-stained Tomato with Nestin, an intermediate filament protein expressed in many stem cell populations (Wiese et al., 2004), including a multipotent population of perivascular cells of mesonephric origin giving rise to LC, pericytes and smooth muscle cells (Jiang et al., 2014; Kumar and DeFalco, 2018). Our analysis of testes at E12.5 and E13.5 reveals some co-labelling, suggesting that some $W_{n t 5 a^{+}}$steroidogenic progenitors may have a perivascular origin (Figure S4).

Considering LCs, few differentiated FLCs expressing the 3 $\beta$ HSD marker were detected at E12.5 (Figure 3P, P'). From E13.5 onward, we observed a rapid increase in the number of Tomato $^{+}$cells co-expressing the LC marker $3 \beta \mathrm{HSD}$, in line with the idea that these progenitors give rise to most of the LCs in the fetal and adult testis (Figure 3Q, Q'). Quantitative analysis (Table 1) revealed that the proportion of double-labelled Tomato $^{+} / 3 \beta \mathrm{HSD}^{+}$FLCs increased from $28 \%$ initially at E12.5 to $56 \%$ at P0, indicating that the majority of FLCs come from Wnt5a-expressing progenitors specified between E11.5 and E12.5. Ultimately, at adult stages the Wnt5a-expressing cells labelled at E11.5-E12.5 represented nearly $71 \%$ of the total number of $3 \beta \mathrm{HSD}^{+} \mathrm{LCs}$.

Overall, this data suggests that the Wnt5 $a^{+}$cells induced by dox between E11.5 and E12.5 initially possess an identity of steroidogenic progenitors. This early pool of $W n t 5 a^{+}$ steroidogenic progenitors decreases over time, although a small proportion persists in adulthood and gives rise to the majority of FLCs and ALCs present in the fetal and adult testes.

$\mathrm{Wnt}_{5} \mathrm{a}^{+}$cells dox-induced at P0-P5 are steroidogenic progenitors that give rise to $17 \%$ of ALCs present in the adult testis

To determine if Wnt5a-expressing cells are still present at early postnatal stages and what their fate is, Wnt5a:Tet-On3G;TetO:Cre;R26:tdTomato new born pups were dox-induced 
for a period of five days (P0-P5) and testes analyzed by immunofluorescence at P5, P20 and P60 (Figure 4). As expected, whole-organ fluorescence analysis revealed a robust signal restricted to the interstitial compartment of postnatal and adult testes (Figure 4AC). At P5, we found that Tomato ${ }^{+}$cells were localized in the interstitium and usually coexpressed the markers NR2F2 and ARX, indicating that Wnt5a-expressing cells are mostly steroidogenic progenitors (Figure 4D-L). At later stages, we observed a drastic decrease in cells co-expressing Tomato and ARX, although they were still present in low numbers, suggesting the persistence of a pool of steroidogenic progenitors in adulthood. For Leydig cells, double immunofluorescence analysis revealed that co-expression of the LC marker $3 \beta \mathrm{HSD}$ and Tomato at P5 was rare and these cells represented only $1.9 \%$ of $3 \beta \mathrm{HSD}^{+}$cells (Figure 4M-R and Table 1). These results are consistent with the observation that Wnt5a expression is restricted to steroidogenic progenitors and not LCs. In contrast, we observed that the proportion of LCs co-expressing Tomato increased to $4.0 \%$ at P20 and then to $17.0 \%$ in adult testis at P60 (Figure 4N-O, Q-R and Table 1).

Overall, this data indicates that the $W n t 5 a^{+}$cells induced by dox between P0 and P5 initially possess an identity of steroidogenic progenitors whose numbers decrease drastically over time, although a small proportion persist into adulthood. This pool of postnatal Wnt5a steroidogenic progenitors ultimately gives rise to a small proportion (17\%) of ALCs present in the adult testes.

\section{A 12-day induction window between E11.5 and P5 reveals that $W n t 5 a^{+}$cells give rise to $\sim 90 \%$ of the LCs present in the adult testis}

It remains unclear whether the pool of $W_{n t 5 a^{+}}$steroidogenic progenitors is generated within a short window of development at around E11.5-E12.5, or whether these cells appear over an extended period covering the second part of fetal development and the early postnatal period. To answer this question and evaluate the overall contribution of the $W n t 5 a^{+}$progenitors to interstitial cells during testicular development, Wnt5a:TetOn3G;TetO:Cre;R26:tdTomato embryos were dox-induced for an extended period of 12 days, from E11.5 to P5. Testes were then analyzed by immunofluorescence at P5 and P60, and the proportion of tomato-positive LCs was quantified (Figure 5). As expected, we found that Tomato ${ }^{+}$cells were localized exclusively in the interstitium. More surprisingly, 
almost all interstitial cells were Tomato ${ }^{+}$. Concerning LCs, quantitative analysis of double immunofluorescence revealed that at P5 $83 \%$ of the $3 \beta \mathrm{HSD}^{+}$cells were also Tomato ${ }^{+}$. This number increased to $90 \%$ at P60, clearly indicating that Wnt5a-expressing cells are responsible for the vast majority of LCs, whether FLCs or ALCs. (Figure 5 and Table 1). Overall, these results suggest that $W n t 5 a^{+}$cells induced by dox over a 12-day period between E11.5 and P5 ultimately give rise to most of the LCs present in both the fetal testis $(83 \%)$ and the adult testis $(90 \%)$.

\section{Fetal but not post-natal $\mathrm{Wnt}_{5} \mathrm{a}^{+}$progenitors differentiate into peritubular myoid cells}

To determine if $W n t 5 a$-expressing cells give rise to other cell types in the developing testis, and in particular peritubular myoid cells (PMCs), we evaluated the co-expression of Tomato $^{+}$cells with ACTA2 (also called SMA), a marker of PMCs and vascular smooth muscle cells. To this end, we investigated the presence of double-positive cells for Tomato and ACTA2 in testes at P5 and P60, in animals whose Wnt5a-expressing cells were labelled by dox induction during three different time periods, namely E11.5-E12.5, E11.5-P5 or P0P5. With regard to fetal induction (E11.5-E12.5 and E11.5-P5), we found that the vast majority of cells expressing the PMC marker ACTA2 co-expressed Tomato at both P5 and P60 (Figure 6A,B,D,E). In contrast, late induction at P0-P5 revealed a lack of co-labelling with ACTA2 (Figure 6C,F). These results indicate that the fate of $W n t 5 a^{+}$progenitors is plastic and that only progenitors expressing Wnt5a during the fetal period are able to differentiate into PMCs.

\section{$W n t 5 a^{+}$adult Leydig cells are proliferating at a low rate}

In order to evaluate whether Wnt5a is still expressed in the adult testis and if so in which cell type, we analyzed scRNA-seq data from adult mouse testis (see (Ernst et al., 2019) and Material \& Methods). Although the majority of testicular cells in this transcriptomic atlas are composed of germ cells at different stages of spermatogenesis, we identified a group of 828 ALCs based on the expression of the markers Insl3 and Hsd3bl (which encodes $3 \beta H S D$ ) (Figure 7A,B \& D,E). Wnt5a is expressed at detectable levels only in ALCs and, more specifically, in a subset of ALCs (Figure 7C \& F). Further analysis suggests no 
substantial transcriptomic differences between these two ( $W n t 5 a^{+}$and $\left.W n t 5 a^{-}\right)$populations, indicating that $W n t 5 a^{+}$ALCs are likely to be representative of ALCs as a whole. To study the fate of $W n t 5 a^{+}$ALCs in the adult testis, Wnt5a:TetOn3G;TetO:Cre;R26:tdTomato adult males were induced with dox for 5 consecutive days at P60. At P65, whole-organ fluorescence analysis revealed rare and scattered signals in the testicular interstitium (Figure 7G \& J). The signal profile is similar after 20 days and 4 months (at P85 and P180, respectively), although the positive cells appear more frequently and are often clustered at the later stage (Figure 7H,I \& K,L). A double labelling by immunofluorescence for Tomato and 3 $\beta \mathrm{HSD}$ reveals that at P65, the rare Tomato $^{+}$cells detected were also $3 \beta \mathrm{HSD}^{+}$and located in the interstitial compartment (Figure 7M). Consistent with our scRNA-seq expression data, these cells display all the characteristics of ALCs. Taking advantage of the rare and scattered Tomato ${ }^{+}$labelling of ALCs present in the adult testis at P65, we decided to use it to trace the fate of these cells. While at P65, Tomato $^{+}$ALCs were rare and isolated, at P180 we observed Tomato ${ }^{+}$ALCs located in clusters, usually near blood vessels, suggesting clonal expansion (Figure $7 \mathbf{N}$, O). Quantitative analysis of immunofluorescence data indicated that the fraction of double Tomato- and 3ßHSD-labelled ALCs in physiological conditions increased from $0.5 \%$ at P65 to $2.4 \%$ at P85 and finally $3.3 \%$ at P180, reflecting an increase in the proportion of Tomato $^{+}$ALCs of more than 6-fold (see Table 1). Clonal proliferation will result in the presence of clusters of Tomato ${ }^{+}$cells whose constituent cells will be very close to each other. If this is indeed the case, we should observe a reduction in the mean distance between Tomato $^{+}$cells between P65 and P180 as a consequence of clonal proliferation. As predicted, spatial analysis revealed that the mean distance between Tomato $^{+}$ALCs decreased significantly from $242 \mu \mathrm{m}$ at P65 to $164 \mu \mathrm{m}$ at P85 and $79 \mu \mathrm{m}$ at P180 $(\mathrm{F}(2.39)=4.16, \mathrm{p}=0.023)$ (Figure 70). A post-hoc analysis based on Tukey's multiple comparison test showed a significant difference between P65 and P180 ( $\mathrm{p}=0.0172)$. Overall, these results suggest that $W n t 5 a^{+}$ALCs physiologically proliferate at a slow pace in the adult testis. 


\section{Discussion}

Understanding the steroidogenic lineage(s) through which testosterone-producing cells are formed is a fundamental question in developmental and reproductive biology. Several technical challenges are associated with the study of steroidogenic progenitors in developing gonads. First, early specific markers are scarce, usually not specific and rarely linked with function. In addition, these steroidogenic progenitors operate in a dynamic environment influenced by intrinsic factors and environmental cues that alter their transcriptome and cell fate. In the present study, we combined single cell transcriptomics with inducible genetic lineage tracing to study the steroidogenic cell lineage in male mice, dissecting the developmental dynamics of steroidogenic progenitors under physiological conditions in fetal, perinatal and adult environments. Overall, our observations support the idea that Wnt5a expressing cells are bona fide LC progenitors and give rise to the majority of FLCs $(80 \%)$ and ALCs $(90 \%)$. We found that the fate of these progenitors varies according to the stage at which these cells express Wnt5a. More precisely, in the course of embryonic and postnatal testis development, the Wnt5a lineage potential become increasingly restricted. While fetal Wnt5a-expressing progenitors will give rise to FLCs, ALCs and PMCs, those expressing Wnt5a post-natally mostly differentiate into ALCs. Finally, in the adult testis, Wnt5a expression is restricted to a small subset of LCs. In vivo lineage tracing revealed that these cells proliferate at a low rate and potentially serve to replenish and maintain the LC population in the adult testis.

\section{The use of the non-canonical Wnt5a as a marker of steroidogenic progenitor lineage} WNT5A, a member of the wingless-related MMTV integration site (WNT) family, functions as a secreted morphogen and is associated with a wide range of developmental processes including differentiation and proliferation (He et al., 2008; Huang et al., 2009; Kim et al., 2005; Serra et al., 2011; Warr et al., 2009; Yamaguchi et al., 1999). In the developing testis, Wnt5a is expressed in interstitial cells of the differentiating testis, starting at around E11.5-E12.5 in a dorso-ventral gradient (see (Chawengsaksophak et al., 2012) and Figure 1). Consistent with its expression profile, our findings confirm that $W n t 5 a^{+}$ cells are true steroidogenic progenitors giving rise to most FLCs and ALCs. Other genes expressed in steroidogenic progenitors might also have been potential candidates to use for 
genetically tracing the lineage of these cells, including Nr5al, Nr2f2/CouptfII, Pdgfra and Tcf21/Podl (Brennan et al., 2003; Shen et al., 2020). However, the expression of these genes is not restricted to the steroidogenic progenitors and they usually display a more widespread expression, either at earlier stages of development and/or in other cell types. Consequently, $\mathrm{Nr}_{5 \mathrm{al}}{ }^{+}, \mathrm{Tcf} 2 \mathrm{I}^{+}, \mathrm{Nr} 2 \mathrm{f2}^{+}, \mathrm{Nestin}^{+}$or $\mathrm{Pdgfra}{ }^{+}$cells contribute to numerous somatic cell types in the testis and are not restricted to the steroidogenic lineage. Tcf 21 , encodes a basic helix-loop-helix transcription factor that is expressed in somatic cells of the bipotential gonadal ridge and is known to be important for testis development (Barsoum et al., 2009; Cui et al., 2004; Lu et al., 2000; Lu et al., 2002; Quaggin et al., 1999). Comparison of $T c f 21$ and Wnt5a expression in the $\mathrm{Nr}_{5} \mathrm{al}^{+}$somatic cell lineage using scRNA-seq data revealed that $T c f 21$ is expressed as early as E10.5 in $\mathrm{Nr}_{5} \mathrm{al}^{+}$progenitors, a stage when these cells are still multipotent and can differentiate into both the supporting and steroidogenic cell lineage (Supplementary Figure S5). In contrast, Wnt5a expression is initiated at a later stage (E12.5). This difference in expression explains why early $T c f 21^{+}$ progenitors contribute to all known somatic population of the testis such as Sertoli cells, PMCs and LCs (Shen et al., 2020), while the fate of $W n t 5 a^{+}$progenitors is mainly restricted to FLCs and ALCs, as reported here.

\section{$\mathrm{Wnt} \mathrm{a}^{+}$cells are steroidogenic progenitors giving rise to the large majority of FLCs and ALCs}

At least two different sources of steroidogenic progenitors give rise to FLCs and ALCs: the $\mathrm{Nr} \mathrm{al}^{+} \mathrm{CE}$-derived and the $\mathrm{Nestin}^{+}$perivascular-derived progenitors. Our analysis by scRNA-seq focused only on the Nr5al lineage. However, it may be possible that Wnt5a is also express in $\mathrm{Nestin}^{+}$progenitors and may represent a more global marker for all classes of steroidogenic progenitors. Consistent with this hypothesis, we found that about $80 \%$ of the FLCs and $90 \%$ of the ALCs are derived from the $W n t 5 a^{+}$progenitors when doxinduction is extended for a long period (E11.5 to P5). In vivo lineage tracing of Nestin ${ }^{+}$ progenitors revealed that $\sim 33 \%$ of FLCs and $\sim 50 \%$ ALCs were derived from these Nestin ${ }^{+}$ progenitors (Kumar and DeFalco, 2018). Taken together, our findings suggest that Wnt5a is a defining steroidogenic progenitor marker expressed in both $\mathrm{Nr}_{5} \mathrm{al}^{+} \mathrm{CE}$-derived and Nestin $^{+}$perivascular-derived progenitors. This hypothesis is supported by our RNAscope 
in situ hybridization data from E12.5 embryos, which clearly indicated the presence of Wnt5a transcripts in both the mesonephros and the interstitial compartment of the testis (Figure 2I).

\section{The fate of $\mathrm{Wnt}^{\mathrm{a}} \mathrm{a}^{+}$progenitors is plastic and varies according to the stage at which these cells express Wnt5a}

Our results revealed that the fate of $W n t 5 a^{+}$progenitors varies depending on the developmental stage at which these cells express Wnt5a. The Wnt5a progenitors may either maintain their progenitor status or differentiate into LCs or PMCs. This is particularly noticeable when we compare the fate of Tomato $^{+}$following dox induction performed in different developmental windows. While progenitor cells expressing Wnt5a during the fetal period give rise to LCs and PMCs, cells expressing Wnt5a in the early postnatal stage (P0P5) differentiate almost exclusively into LCs. Thus, only progenitors expressing Wnt5a between E11.5 and P0 are able to differentiate into PTM cells (see Figure 6). This suggests that Wnt5a expressing cells are initially multipotent with several potential fates such as remaining progenitors or differentiating into FLCs, ALCs or PMCs, then later the fate is restricted to give almost exclusively ALCs. The findings that PMCs are largely derived from $W n t 5 a^{+}$progenitors is not entirely surprising, as other recent lineage tracing studies investigating the fate of steroidogenic progenitors using markers such as Nestin or Tcf 21 obtained similar results (Kumar and DeFalco, 2018; Shen et al., 2020). In addition, another evidence indicative of a common progenitor is the role of $\mathrm{DHH}$, a paracrine factor secreted by Sertoli cells, which is responsible for the differentiation of both PMCs and LCs (Pierucci-Alves et al., 2001; Yao et al., 2002). Dhh-null mice develop abnormal peritubular myoid and Leydig cells. However, it is currently unclear how this single multipotent steroidogenic progenitor is able to commit to a PMC or FLC fate and what testicular factors favor one fate over the other.

\section{$W n t 5 a^{+}$Leydig cell undergo rare events of cellular divisions in adult testis}

In adult testes, our scRNAseq and genetic lineage tracing results clearly indicate that Wnt5a is expressed in a small fraction of the ALCs. We also found that these Wnt $5 a^{+}$ALCs undergo rare events of cell division in adult testis. This is particularly surprising because 
the current dogma clearly states that LCs do not proliferate, but instead originate from steroidogenic progenitor cells that proliferate and then differentiate into FLCs or ALCs (Hardy et al., 1989; Miyabayashi et al., 2013; Vergouwen et al., 1991). Our analyses based on scRNA-seq data did not reveal obvious transcriptional differences between $W n t 5 a^{+}$and Wnt5 $a^{-}$ALCs populations, suggesting that ALCs are a homogenous population. To our knowledge, the only data suggesting potential renewal of LCs in the adult testis come from a study by Teerds et al (Teerds et al., 1989), which examined the renewal of Leydig and other interstitial cells in the adult rat testis by injecting $3 \mathrm{H}$-thymidine twice daily for 1,3 and 8 days. The percentage of labelled ALCs, which was initially low (0.5\%), gradually increased during treatment to $1.4 \%$. Our data are consistent with data from Teerds et al. and suggest that $W n t 5 a^{+}$ALCs contribute to steroidogenic cell numbers in adult testes. Alternatively, it remains a theoretical possibility that $W n t 5 a^{+}$ALCs de-differentiate into progenitor cells under physiological conditions in order to be able to reenter into the cell cycle, expand the progenitor pool and subsequently re-differentiate into ALCs. In both cases, this slow renewal process is remarkable, as it provides evidence of LC regeneration under physiological conditions. The fact that differentiated testosterone-producing cells can proliferate could have far-reaching implications in understanding and possibly treating patients with primary hypogonadism or late hypogonadism, where androgen biosynthesis is defective due to impaired LC function. 


\section{STAR Methods}

Key Resources Table (see attached document)

\section{Contact for Reagent and Resource Sharing}

Further information and requests for resources and reagents should be directed to and will be fulfilled by the Lead Contact, Serge Nef (serge.nef@unige.ch).

\section{Method details}

\section{Animals}

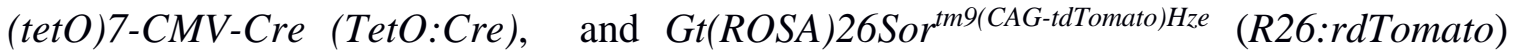
transgenic animals were described previously (Madisen et al., 2010; Perl et al., 2002). The Wnt5a $a^{\text {tml(Tet-On } 3 G) N e f}$ strain was obtained by inserting the $1.2 \mathrm{~kb}$ Tet-On $3 G$ sequence 8 nucleotides after the ATG and $0.8 \mathrm{~kb}$ downstream of the Wnt5a initiation of transcription using the CrispR/Cas9 system (see Sup. Material \& Methods for more details). Routine genotyping of the transgenic lines was performed by classic PCR using sets of primers specific for the TetO-Cre and R26:tdTomato transgenes as described previously, or a set of primers for Wnt5 $a^{\text {tml(Tet-On } 3 G) N e f}$ genotyping (see Sup. Material \& Methods). To analyze the fate of Wnt5a-expressing cells, we performed lineage tracing using Wnt5a $a^{\text {tml(Tet- }}$ ${ }^{\text {On3G)Nef; }}$ (tetO)7-CMV-Cre ${ }^{\text {TG/+ }} ; \mathrm{R}_{2} 6^{\text {tdTOMATO/+ }}$ mice later abbreviated Wnt5a:TetON3G;TetO-Cre;R26:tdTomato for simplicity. Wnt5a $a^{\text {Tet-On }}{ }^{3 G /+} ;$ TetO$\mathrm{Cre}^{\text {TG/+}} ; \mathrm{R}^{2} 6^{\text {tdTOMATO/+}}$ were considered as positive whereas $\mathrm{Wnt} 5 \mathrm{a}^{\text {Tet-On3G/+}} ;$ TetO-

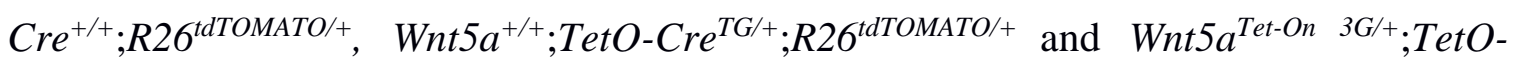
$\mathrm{Cre}^{T G /+} ; \mathrm{R}^{\text {tdTOMATO+/+ }}$ were considered as negative controls. DOX was administered in drinking water $(\mathrm{pH} \mathrm{6.5})$ at a concentration of $2 \mathrm{mg} / \mathrm{mL}$. Animals were then sacrificed at different time points to monitor the fate of Wnt5a expressing cells during testicular development and in adulthood. The animals were treated with care and respect. This study complies with all ethical rules applicable to animal research and all experiments were approved and conducted in accordance with the guidelines of the Service de la consommation et des affaires vétérinaires du Canton de Genève (licence numbers GE/67/19 and GE/105/18). 


\section{Single cell RNA sequencing and analysis}

Single-cell RNA sequencing for $\mathrm{Nr}_{5} \mathrm{al}^{+}$cells in fetal gonads was generated as described in (Stevant et al., 2019; Stevant et al., 2018). Briefly, somatic cells of developing XY mouse gonads were purified by sorting gonadal cells from $\operatorname{Tg}(\mathrm{Nr} 5 \mathrm{al}$ :GFP) embryos at 5 stages of development (E10.5, E11.5, E12.5, E13.5, and E16.5) using FACS BD ARIA II. Single-cell isolation, reverse transcription and cDNA amplification was performed using the Fluidigm C1 Autoprep system on the 96 well IFC chips, and single-cell sequencing libraries were prepared with Illumina Nextera XT following the Fluidigm protocol. Libraries were multiplexed and sequenced on an Illumina HiSeq2000 platform with 100bp paired-end reads, at an average depth of 10 million reads per single-cell. Obtained reads were mapped on the mouse reference genome (GRCm38.p3) and gene expression normalized and quantified in RPKMs (Reads Per Kilobase of exon per Million reads mapped). Cells were clustered with R using PCA and hierarchical clustering, and cell types were identified according to the expression level of marker genes and gene ontology enrichment tests.

10X scRNA-seq data of adult (age 8-10 weeks) mouse testes from Ernst et al. 2019 was pre-processed with CellRanger Count to map the sequencing reads to the GRCm38 mouse reference genome with GENCODE M15 transcriptome annotation (Ernst et al., 2019). This resulted in a filtered cells vs. genes matrix. Using Scanpy (Wolf et al., 2018), cells with fewer than 50 genes expressed and genes expressed in fewer than 3 cells were filtered out. Expression counts were normalized and log-transformed. Highly variable genes were identified. The top 50 PCA components were embedded in the neighbourhood graph with batch correction via BBKNN (Polanski et al., 2020) and the data was visualized with 2D UMAPs (McInnes et al., 2018). Cell clusters were defined with the Leiden algorithm (Traag et al., 2019) and the population of LCs was identified based on the expression of the classical marker genes Insl3 and $H s d 3 b 1$. Computations were performed on the Baobab HPC cluster at the University of Geneva.

\section{Immunostainings and RNAscope ${ }^{\circledR}$ in situ hybridization}


Mouse embryos at E12.5 were collected and fixed overnight in 4\% paraformaldehyde, serially dehydrated, embedded in paraffin and sectioned at 5- $\mu \mathrm{m}$. Co-localization of Wnt5a transcripts and Tomato protein was performed_with the RNAscope ${ }^{\circledR}$ 2.5 LS Assay-RED kit (ACDBio) according to manufacturer's instructions for soft tissues. The RNAscope probe used in this study is $M m$-Wnt5a (ACDBio). Images were acquired with ZEISS LSM800 confocal microscope equipped with a plan-apochromat 10x 0.45NA objective $(0.624 \mu \mathrm{m} / \mathrm{pixel})$ or with a $40 \mathrm{x} 1.4 \mathrm{NA}$ oil immersion objective $(0.156 \mu \mathrm{m} / \mathrm{pixel})$.

\section{Flow cytometry, RNA extraction and quantitative RT-PCR}

$\mathrm{XX}$ and XY gonads of Wnt5a:Tet-On3G;TetO:Cre;R26:tdTOMATO animals were collected at E12.5, E16.5 and P5. Testis or ovaries were dissociated in trypsin-EDTA $0.05 \%$ at $37^{\circ} \mathrm{C}$ for up to 10 minutes under rapid agitation. Cell suspensions were resuspended in $0.5 \mathrm{ml}$ of DPBS and filtered through a $70-\mu \mathrm{m}$ cell strainer (BD Falcon; BD Biosciences Discovery Labware, Bedford, Massachusetts) for fluorescent activated sorting (FACS) using a Cell sorter S3 (Bio-rad, Berkeley, California). The gating strategy consisted in debris exclusion (SSC vs FCS), dead cell exclusion (FCS vs Draq7 fluorescence intensity) and doublet exclusion (FSC height vs FSC area). Finally, Tomatonegative and -positive cell fractions were gated using the intensity on the FL1 channel. In E12.5 males, we detected on average $60 \%$ of Tomato $^{+}$cells, whereas only $40 \%$ and $5 \%$ were detected at E16.5 and P5, respectively.

For RNA extraction, pools of 40.000 FACS-sorted Tomato $^{+}$or Tomato $^{-}$cells were extracted using an RNeasy MicroKit (Qiagen, Valencia, California), according to the manufacturer's protocol. RNA integrity and quantity were assessed using RNA 6000 picochips with a 2100 bioanalyzer (Agilent Technologies, Santa Clara, California) before and after genomic DNA removal with DNaseI digestion. 500pg to 1ng of total RNAs was reverse-transcribed with random hexamers using the M-MLV reverse transcriptase (Promega, Madison, USA). A selection of relevant genes (Wnt5a, Nr2f2, Arx, Amh, Cyp1 1al, Actb, Tubala, Gadph) were pre-amplified with the Prelude PreAmp Master Mix (Takara, Shiga, Japan). Real-time RT-PCR was performed on each sample in triplicate using KAPA SYBRFast (Kapa Biosystems, Wilmington, MA, USA) and a Corbett RotorGene 6000 (Qiagen, Valencia, California). Data was analyzed using a comparative critical 
threshold (CT) method with the amount of target gene normalized to the average of 3 endogenous control genes (Actb and Tubala and Gadph). The primers used for qRT-PCR are listed in Table $\mathbf{S 4 .}$

\section{Histological and immunological analyses}

Embryos were fixed overnight at $4{ }^{\circ} \mathrm{C}$ in $4 \%$ paraformaldehyde, dehydrated in an ethanol series and embedded in paraffin. Five $\mu \mathrm{m}$-sections were stained with hematoxylin and eosin $(\mathrm{H} \& \mathrm{E})$ or processed for immunofluorescence (IF). For IF analysis, antigen retrieval was performed either in TEG buffer $(10 \mathrm{mM}, \mathrm{pH}$ ) $)$ or sodium citrate buffer $(10 \mathrm{mM}, \mathrm{pH}$ 6) for 15 minutes in a pressure cooker. Sections were incubated in blocking reagent (3\% bovine serum albumin, $0.1 \%$ tween in PBS) for 2 hours at room temperature, and primary antibodies incubated overnight at $4^{\circ} \mathrm{C}$. Slides were counterstained with DAPI and mounted with PBS:glycerol (1:1). Fluorescent images were acquired using Axio Scope.A1 microscope fitted with an AxiocamMRc camera (Carl Zeiss, Oberkochen, Germany) and processed using the Zen software (Carl Zeiss).

\section{Cell counting}

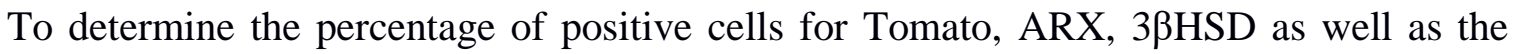
double labeled Tomato/ARX or Tomato/3ßHSD cells, we scanned the IF sections. In short, fluorescent images of double IF (Tomato/ARX and Tomato/3 $\beta$ HSD) were acquired with a slide scanner Axio Scan.Z1 (ZEISS, Oberkochen, Germany) using a Plan-Apochromat 20x/0.8 objective $(0.325 \mu \mathrm{m} / \mathrm{pixel})$. Whole testis images were analyzed using QuPath v0.2.0 (Bankhead et al., 2017) to extract fluorescent intensities within all the detected cells. The cellular information was then processed with MATLAB R2019b (The Mathworks, Natick, Massachusetts, USA), to classify cells into red and green positive ones if their respective fluorescent intensities and homogeneities were above user defined thresholds. Then the variation of red and green positive cells through time was expressed as a percentage of positive cells within the population. For all experiments and stages, three to five different sections, from at least three independent gonads from different animals were used. Detail of total cell counts are included in Table 1. Subsequently, for the 3ßHSD and Tomato experiments, the proximity was assessed based on the pairwise Euclidean distance 
between pairs of all Tomato positive cells. The mean distance of the 3 nearest neighbors of each cell was computed and averaged per section also allowing us to appraise the proximity of changes through time.

\section{Acknowledgments:}

We thank Antonella Rauseo and Juliette Cicchini-Bauquis for their help in animal handling, genotyping and immunofluorescence experiments, Fabrizio Thorel and Olivier Fazio from the transgenesis platform for their help in the generation of the transgenic knock-in line Wnt5a:Tet-On3G (Faculty of Medicine, University of Geneva), the animal facility team (Faculty of Medicine, University of Geneva), Jean-Pierre Aubry, Cécile Gameiro and Grégory Schneiter of the flow cytometry platform, the genomic platform and Nicolas Liaudet of the bioimaging platform (Faculty of Medicine, University of Geneva) for his substantial contribution with the counting and cell inter-distance analysis. We thank also the members of the Nef laboratory for helpful discussion and critical reading of the manuscript.

\section{Author Contributions}

Conceptualization, H.A. and S.N.; Methodology: H.A. and B.C., Investigation, H.A.; Formal Analysis and Data Curation, H.A., I.S., C.M.R.; Writing - Original Draft, H.A. and S.N.; Funding Acquisition, S.N.; Resources, S.N.; Supervision, S.N.

\section{Competing Interests}

The authors declare no competing or financial interests.

\section{Fundings}

This work was supported by grants from the Swiss National Science Foundation (grants 31003A_173070 and 51PHI0-141994) and by the Département de l'Instruction Publique of the State of Geneva (to S.N.). 


\section{References}

Albrecht, K.H., and Eicher, E.M. (2001). Evidence that Sry is expressed in pre-Sertoli cells and Sertoli and granulosa cells have a common precursor. Dev Biol 240, 92-107.

Bankhead, P., Loughrey, M.B., Fernandez, J.A., Dombrowski, Y., McArt, D.G., Dunne, P.D., McQuaid, S., Gray, R.T., Murray, L.J., Coleman, H.G., et al. (2017). QuPath: Open source software for digital pathology image analysis. Sci Rep 7, 16878.

Barsoum, I., and Yao, H.H. (2006). The road to maleness: from testis to Wolffian duct. Trends in endocrinology and metabolism: TEM 17, 223-228.

Barsoum, I.B., Bingham, N.C., Parker, K.L., Jorgensen, J.S., and Yao, H.H. (2009). Activation of the Hedgehog pathway in the mouse fetal ovary leads to ectopic appearance of fetal Leydig cells and female pseudohermaphroditism. Dev Biol 329, 96-103.

Barsoum, I.B., Kaur, J., Ge, R.S., Cooke, P.S., and Yao, H.H. (2013). Dynamic changes in fetal Leydig cell populations influence adult Leydig cell populations in mice. FASEB J 27, 2657-2666.

Barsoum, I.B., and Yao, H.H. (2010). Fetal Leydig cells: progenitor cell maintenance and differentiation. J Androl 31, 11-15.

Bitgood, M.J., Shen, L., and McMahon, A.P. (1996). Sertoli cell signaling by Desert hedgehog regulates the male germline. Curr Biol 6, 298-304.

Brennan, J., Tilmann, C., and Capel, B. (2003). Pdgfr-alpha mediates testis cord organization and fetal Leydig cell development in the XY gonad. Genes Dev 17, 800-810.

Byskov, A.G. (1986). Differentiation of mammalian embryonic gonad. Physiological reviews 66, 71-117.

Chawengsaksophak, K., Svingen, T., Ng, E.T., Epp, T., Spiller, C.M., Clark, C., Cooper, H., and Koopman, P. (2012). Loss of Wnt5a disrupts primordial germ cell migration and male sexual development in mice. Biol Reprod 86, 1-12.

Chen, H., Jin, S., Huang, S., Folmer, J., Liu, J., Ge, R., and Zirkin, B.R. (2016). Transplantation of alginate-encapsulated seminiferous tubules and interstitial tissue into adult rats: Leydig stem cell differentiation in vivo? Mol Cell Endocrinol 436, 250-258.

Chen, H., Wang, Y., Ge, R., and Zirkin, B.R. (2017). Leydig cell stem cells: Identification, proliferation and differentiation. Mol Cell Endocrinol 445, 65-73.

Cui, S., Ross, A., Stallings, N., Parker, K.L., Capel, B., and Quaggin, S.E. (2004). Disrupted gonadogenesis and male-to-female sex reversal in Pod1 knockout mice. Development 131, 40954105.

Davidoff, M.S., Middendorff, R., Enikolopov, G., Riethmacher, D., Holstein, A.F., and Muller, D. (2004). Progenitor cells of the testosterone-producing Leydig cells revealed. J Cell Biol 167, 935944.

DeFalco, T., Takahashi, S., and Capel, B. (2011). Two distinct origins for Leydig cell progenitors in the fetal testis. Dev Biol 352, 14-26.

Eliveld, J., van den Berg, E.A., Chikhovskaya, J.V., van Daalen, S.K.M., de Winter-Korver, C.M., van der Veen, F., Repping, S., Teerds, K., and van Pelt, A.M.M. (2019). Primary human testicular PDGFRalpha+ cells are multipotent and can be differentiated into cells with Leydig cell characteristics in vitro. Hum Reprod 34, 1621-1631.

Ernst, C., Eling, N., Martinez-Jimenez, C.P., Marioni, J.C., and Odom, D.T. (2019). Staged developmental mapping and $\mathrm{X}$ chromosome transcriptional dynamics during mouse spermatogenesis. Nat Commun 10, 1251.

Ge, R.S., Dong, Q., Sottas, C.M., Papadopoulos, V., Zirkin, B.R., and Hardy, M.P. (2006). In search of rat stem Leydig cells: identification, isolation, and lineage-specific development. Proc Natl Acad Sci U S A 103, 2719-2724. 
Gubbay, J., Collignon, J., Koopman, P., Capel, B., Economou, A., Munsterberg, A., Vivian, N., Goodfellow, P., and Lovell-Badge, R. (1990). A gene mapping to the sex-determining region of the mouse $\mathrm{Y}$ chromosome is a member of a novel family of embryonically expressed genes. Nature $346,245-250$.

Habert, R., Lejeune, H., and Saez, J.M. (2001). Origin, differentiation and regulation of fetal and adult Leydig cells. Mol Cell Endocrinol 179, 47-74.

Hacker, A., Capel, B., Goodfellow, P., and Lovell-Badge, R. (1995). Expression of Sry, the mouse sex determining gene. Development 121, 1603-1614.

Haider, S.G. (2004). Cell biology of Leydig cells in the testis. Int Rev Cytol 233, 181-241.

Hardy, M.P., Zirkin, B.R., and Ewing, L.L. (1989). Kinetic studies on the development of the adult population of Leydig cells in testes of the pubertal rat. Endocrinology 124, 762-770.

He, F., Xiong, W., Yu, X., Espinoza-Lewis, R., Liu, C., Gu, S., Nishita, M., Suzuki, K., Yamada, G., Minami, Y., et al. (2008). Wnt5a regulates directional cell migration and cell proliferation via Ror2-mediated noncanonical pathway in mammalian palate development. Development 135, 38713879.

Huang, L., Pu, Y., Hu, W.Y., Birch, L., Luccio-Camelo, D., Yamaguchi, T., and Prins, G.S. (2009). The role of Wnt5a in prostate gland development. Dev Biol 328, 188-199.

Jiang, M.H., Cai, B., Tuo, Y., Wang, J., Zang, Z.J., Tu, X., Gao, Y., Su, Z., Li, W., Li, G., et al. (2014). Characterization of Nestin-positive stem Leydig cells as a potential source for the treatment of testicular Leydig cell dysfunction. Cell Res 24, 1466-1485.

Karl, J., and Capel, B. (1998). Sertoli cells of the mouse testis originate from the coelomic epithelium. Developmental Biology 203, 323-333.

Kerr, J.B., and Knell, C.M. (1988). The fate of fetal Leydig cells during the development of the fetal and postnatal rat testis. Development 103, 535-544.

Kilcoyne, K.R., Smith, L.B., Atanassova, N., Macpherson, S., McKinnell, C., van den Driesche, S., Jobling, M.S., Chambers, T.J., De Gendt, K., Verhoeven, G., et al. (2014). Fetal programming of adult Leydig cell function by androgenic effects on stem/progenitor cells. Proc Natl Acad Sci U S A 111, E1924-1932.

Kim, H.J., Schleiffarth, J.R., Jessurun, J., Sumanas, S., Petryk, A., Lin, S., and Ekker, S.C. (2005). Wnt5 signaling in vertebrate pancreas development. BMC Biol 3, 23.

Koopman, P., Munsterberg, A., Capel, B., Vivian, N., and Lovell-Badge, R. (1990). Expression of a candidate sex-determining gene during mouse testis differentiation. Nature 348, 450-452.

Kumar, D.L., and DeFalco, T. (2018). A perivascular niche for multipotent progenitors in the fetal testis. Nat Commun 9, 4519.

Lovell-Badge, R., and Robertson, E. (1990). XY female mice resulting from a heritable mutation in the primary testis-determining gene, Tdy. Development 109, 635-646.

Lu, J., Chang, P., Richardson, J.A., Gan, L., Weiler, H., and Olson, E.N. (2000). The basic helixloop-helix transcription factor capsulin controls spleen organogenesis. Proc Natl Acad Sci U S A 97, 9525-9530.

Lu, J.R., Bassel-Duby, R., Hawkins, A., Chang, P., Valdez, R., Wu, H., Gan, L., Shelton, J.M., Richardson, J.A., and Olson, E.N. (2002). Control of facial muscle development by MyoR and capsulin. Science 298, 2378-2381.

Madisen, L., Zwingman, T.A., Sunkin, S.M., Oh, S.W., Zariwala, H.A., Gu, H., Ng, L.L., Palmiter, R.D., Hawrylycz, M.J., Jones, A.R., et al. (2010). A robust and high-throughput Cre reporting and characterization system for the whole mouse brain. Nat Neurosci 13, 133-140.

McInnes, L., Healy, J., and J., M. (2018). UMAP: Uniform Manifold Approximation and Projection for Dimension Reduction. arXiv:180203426v2

Migrenne, S., Pairault, C., Racine, C., Livera, G., Geloso, A., and Habert, R. (2001). Luteinizing hormone-dependent activity and luteinizing hormone-independent differentiation of rat fetal Leydig cells. Mol Cell Endocrinol 172, 193-202. 
Miyabayashi, K., Katoh-Fukui, Y., Ogawa, H., Baba, T., Shima, Y., Sugiyama, N., Kitamura, K., and Morohashi, K. (2013). Aristaless related homeobox gene, Arx, is implicated in mouse fetal Leydig cell differentiation possibly through expressing in the progenitor cells. PLoS ONE 8 , e68050.

Patel, S.H., O'Hara, L., Atanassova, N., Smith, S.E., Curley, M.K., Rebourcet, D., Darbey, A.L., Gannon, A.L., Sharpe, R.M., and Smith, L.B. (2017). Low-dose tamoxifen treatment in juvenile males has long-term adverse effects on the reproductive system: implications for inducible transgenics. Sci Rep 7, 8991.

Perl, A.K., Wert, S.E., Nagy, A., Lobe, C.G., and Whitsett, J.A. (2002). Early restriction of peripheral and proximal cell lineages during formation of the lung. Proc Natl Acad Sci U S A 99, 10482-10487.

Pierucci-Alves, F., Clark, A.M., and Russell, L.D. (2001). A developmental study of the Desert hedgehog-null mouse testis. Biol Reprod 65, 1392-1402.

Polanski, K., Young, M.D., Miao, Z., Meyer, K.B., Teichmann, S.A., and Park, J.E. (2020). BBKNN: fast batch alignment of single cell transcriptomes. Bioinformatics 36, 964-965.

Qin, J., Tsai, M.J., and Tsai, S.Y. (2008). Essential roles of COUP-TFII in Leydig cell differentiation and male fertility. PLoS ONE 3, e3285.

Quaggin, S.E., Schwartz, L., Cui, S., Igarashi, P., Deimling, J., Post, M., and Rossant, J. (1999). The basic-helix-loop-helix protein pod1 is critically important for kidney and lung organogenesis. Development 126, 5771-5783.

Rotgers, E., Jorgensen, A., and Yao, H.H. (2018). At the Crossroads of Fate-Somatic Cell Lineage Specification in the Fetal Gonad. Endocr Rev 39, 739-759.

Serra, R., Easter, S.L., Jiang, W., and Baxley, S.E. (2011). Wnt5a as an effector of TGFbeta in mammary development and cancer. J Mammary Gland Biol Neoplasia 16, 157-167.

Shen, Y.-c., Larose, H., Shami, A.N., Moritz, L., Manske, G.L., Ma, Q., Zheng, X., Sukhwani, M., Czerwinski, M., Sultan, C., et al. (2020). Tcf $21<$ sup $>+</$ sup $>$ mesenchymal cells contribute to testis somatic cell development, homeostasis, and regeneration. 2020.2005.2002.074518.

Shima, Y., Matsuzaki, S., Miyabayashi, K., Otake, H., Baba, T., Kato, S., Huhtaniemi, I., and Morohashi, K. (2015). Fetal Leydig Cells Persist as an Androgen-Independent Subpopulation in the Postnatal Testis. Mol Endocrinol 29, 1581-1593.

Shima, Y., Miyabayashi, K., Baba, T., Otake, H., Katsura, Y., Oka, S., Zubair, M., and Morohashi, K. (2012). Identification of an enhancer in the Ad4BP/SF-1 gene specific for fetal Leydig cells. Endocrinology 153, 417-425.

Shima, Y., Miyabayashi, K., Sato, T., Suyama, M., Ohkawa, Y., Doi, M., Okamura, H., and Suzuki, K. (2018). Fetal Leydig cells dedifferentiate and serve as adult Leydig stem cells. Development 145.

Stevant, I., Kuhne, F., Greenfield, A., Chaboissier, M.C., Dermitzakis, E.T., and Nef, S. (2019). Dissecting Cell Lineage Specification and Sex Fate Determination in Gonadal Somatic Cells Using Single-Cell Transcriptomics. Cell Rep 26, 3272-3283 e3273.

Stevant, I., Neirijnck, Y., Borel, C., Escoffier, J., Smith, L.B., Antonarakis, S.E., Dermitzakis, E.T., and Nef, S. (2018). Deciphering Cell Lineage Specification during Male Sex Determination with Single-Cell RNA Sequencing. Cell Rep 22, 1589-1599.

Svingen, T., and Koopman, P. (2013). Building the mammalian testis: origins, differentiation, and assembly of the component cell populations. Genes Dev 27, 2409-2426.

Teerds, K.J., De Rooij, D.G., Rommerts, F.F., van der Tweel, I., and Wensing, C.J. (1989). Turnover time of Leydig cells and other interstitial cells in testes of adult rats. Arch Androl 23, 105-111.

Teerds, K.J., and Huhtaniemi, I.T. (2015). Morphological and functional maturation of Leydig cells: from rodent models to primates. Human reproduction update 21, 310-328. 
Thorel, F., Nepote, V., Avril, I., Kohno, K., Desgraz, R., Chera, S., and Herrera, P.L. (2010). Conversion of adult pancreatic alpha-cells to beta-cells after extreme beta-cell loss. Nature 464, 1149-1154.

Traag, V.A., Waltman, L., and van Eck, N.J. (2019). From Louvain to Leiden: guaranteeing wellconnected communities. Sci Rep 9, 5233.

Vergouwen, R.P., Jacobs, S.G., Huiskamp, R., Davids, J.A., and de Rooij, D.G. (1991). Proliferative activity of gonocytes, Sertoli cells and interstitial cells during testicular development in mice. Journal of reproduction and fertility 93, 233-243.

Warr, N., Siggers, P., Bogani, D., Brixey, R., Pastorelli, L., Yates, L., Dean, C.H., Wells, S., Satoh, W., Shimono, A., et al. (2009). Sfrp1 and Sfrp2 are required for normal male sexual development in mice. Dev Biol 326, 273-284.

Wen, Q., Cheng, C.Y., and Liu, Y.X. (2016). Development, function and fate of fetal Leydig cells. Semin Cell Dev Biol.

Wiese, C., Rolletschek, A., Kania, G., Blyszczuk, P., Tarasov, K.V., Tarasova, Y., Wersto, R.P., Boheler, K.R., and Wobus, A.M. (2004). Nestin expression--a property of multi-lineage progenitor cells? Cell Mol Life Sci 61, 2510-2522.

Wolf, F.A., Angerer, P., and Theis, F.J. (2018). SCANPY: large-scale single-cell gene expression data analysis. Genome Biol 19, 15.

Yamaguchi, T.P., Bradley, A., McMahon, A.P., and Jones, S. (1999). A Wnt5a pathway underlies outgrowth of multiple structures in the vertebrate embryo. Development 126, 1211-1223.

Yao, H.H., Whoriskey, W., and Capel, B. (2002). Desert Hedgehog/Patched 1 signaling specifies fetal Leydig cell fate in testis organogenesis. Genes Dev 16, 1433-1440. 
Figure legends
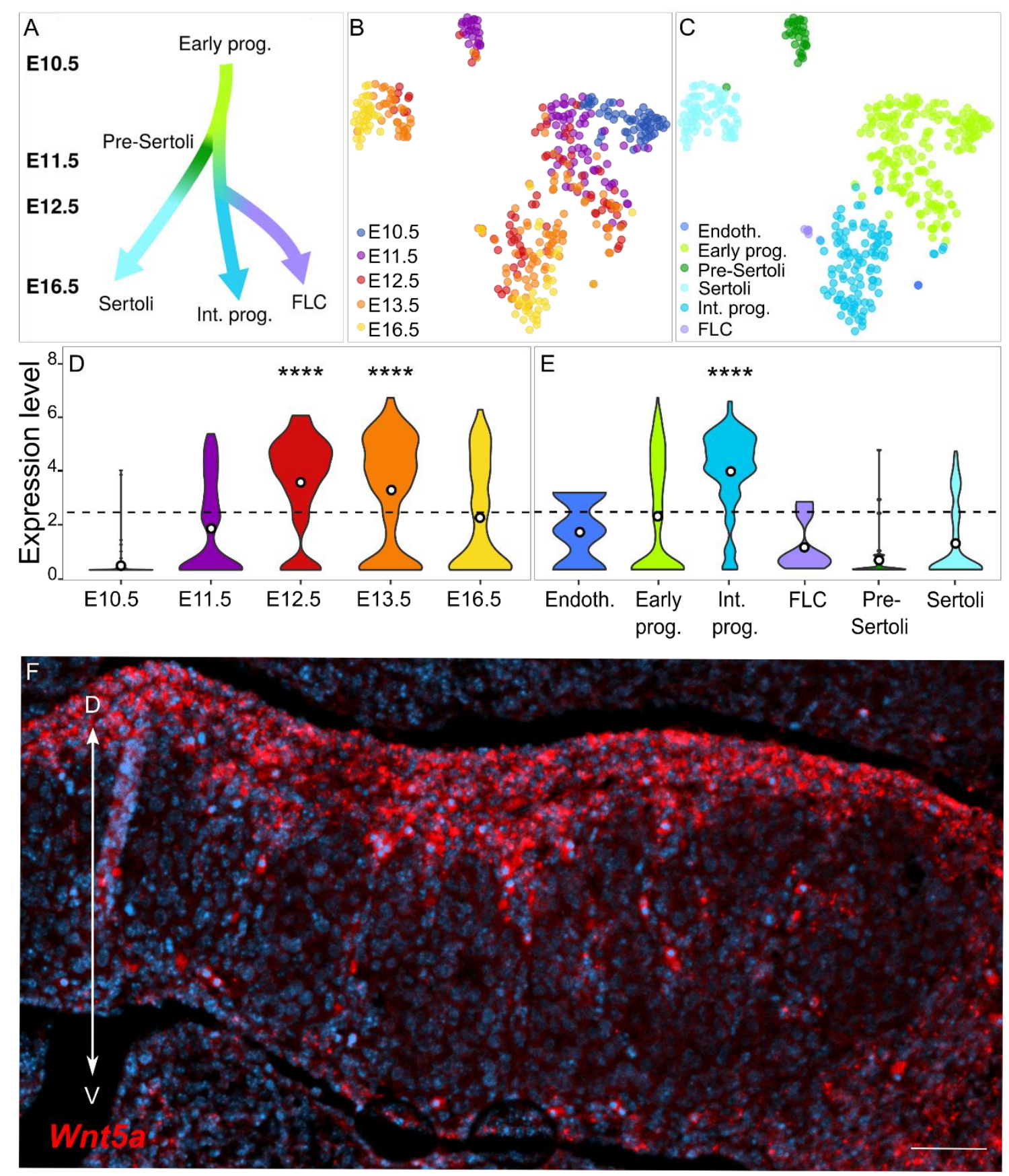

Figure 1: Identification of Wnt5a as a marker of the steroidogenic lineage and validation of its expression profile. (A) Schematic representation of the Nr5al cell lineage at the origin of the supporting and steroidogenic lineages in XY gonads. (B) t-SNE representation of the $400 \mathrm{Nr}^{2} \mathrm{al}^{+}$single cells from $\mathrm{XY}$ developing gonads colored by embryonic stages (B) and by cell clusters (C). Wnt5a expression represented as violin graph 
based on developmental stages (D) and Nr5al cell cluster (E). The width of the "violin" indicates the proportion of the cells at that expression level. Expression scale presented as $\log (\mathrm{RPKM}+1)$. The horizontal dashed lines represent the overall mean of expression, and the white dots in the violins are the mean of expression of the given cell populations. Wnt $5 a$ transcripts are highly expressed in the interstitial steroidogenic progenitors starting at E11.5 but not in the other branches of the Nr5al lineage including early progenitors, preSertoli cells, Sertoli cells and fetal Leydig cells. (F) RNA-Scope analysis revealed a dorsoventral gradient of Wnt5a expression in the interstitial region of developing testis at E12.5. Abbreviations: Endoth., endothelial cells; Early prog., early progenitors; Int. prog., interstitial steroidogenic progenitors; FLC, fetal Leydig cells; Pre-Sertoli, pre-Sertoli cells; Sertoli, Sertoli cells. Difference of expression relative to the mean was assessed using the Wilcoxon test. $* * * * \mathrm{P}<0.0001$. D -- S, dorso-ventral axis. Scale bar (D) $50 \mu \mathrm{m}$. 

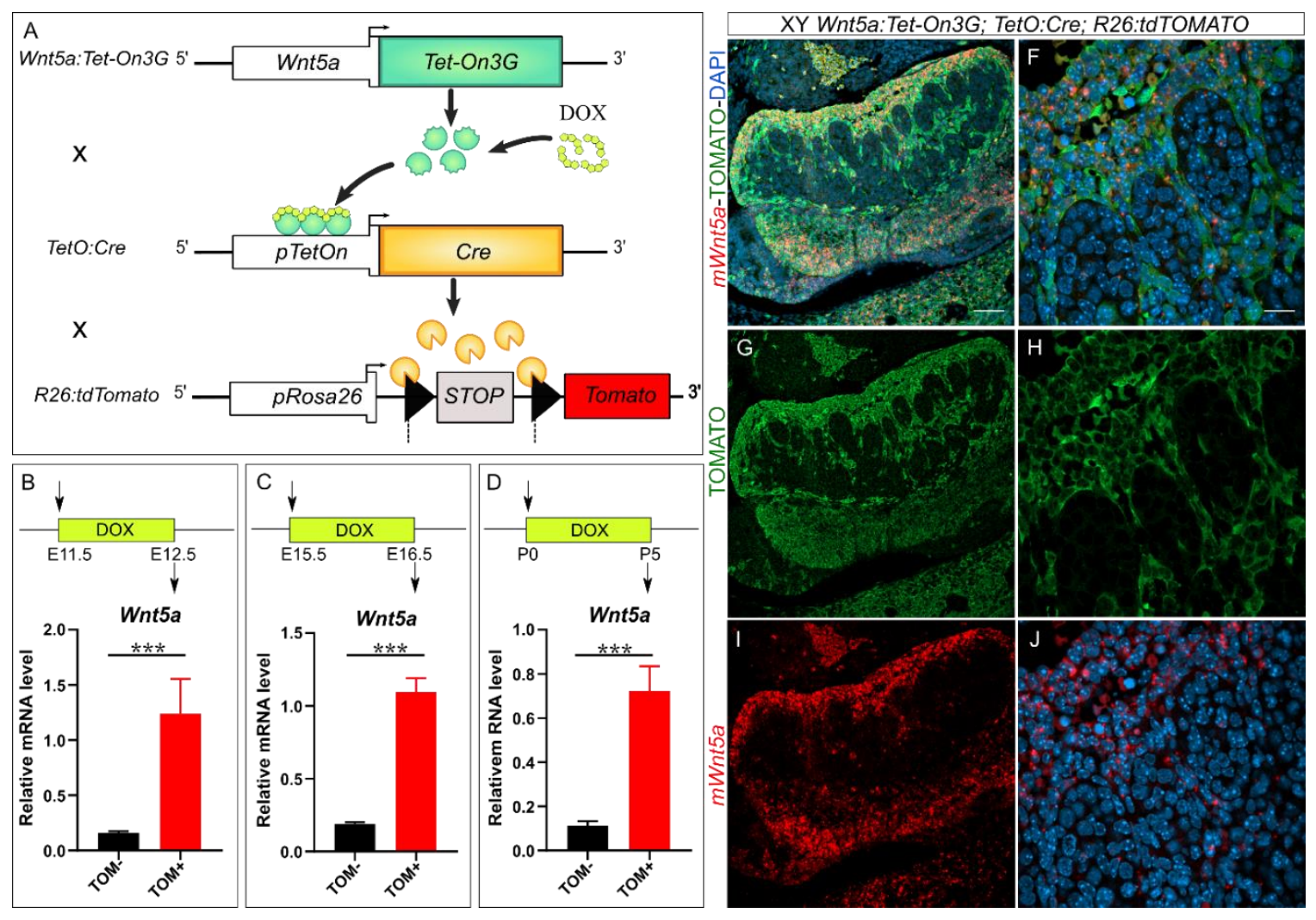

Figure 2: Lineage tracing strategy and assessment of the penetrance and specificity of the mouse model. (A) Schematic description of the lineage tracing strategy. Upon doxycycline (DOX) administration in the drinking water, Wnt5a-expressing cells of triple transgenic animals are permanently labelled by the Tomato marker. (B-D) Assessment of the efficiency and specificity of the labelling of Wnt5a-expressing cells. Quantitative RTPCR performed with total RNAs from Tomato positive $(+)$ or negative $(-)$ cells isolated from triple transgenic testes. Dox labeling was induced either for 24 hours between E11.5 and E12.5 and the Tomato ${ }^{+}$and Tomato ${ }^{-}$cells were isolated by FACs at E12.5 (n=3) (B), between E15.5 and E16.5 and the cells were isolated at E16.5 (n=3) (C), or between P0 and P5 and the cells were isolated at P5 (n=3)(D). Expression profiles were normalized to Actin, Tubulin, Gapdh. *** $\mathrm{P}<0.001$. As expected, Wnt5a transcripts were highly enriched in all the Tomato $^{+}$cell populations. (E-J) RNA-Scope analysis for Wnt5a followed by immunostaining for the Tomato marker reveals co-expression in triple transgenic E12.5 testis dox-induced for 24 hours at E11.5. Nuclei were counterstained with 4',6-diamidino2-phenylindole (DAPI). Abbreviations: $t$, testis; m, mesonephros. Scale bar $50 \mu \mathrm{m}$. 


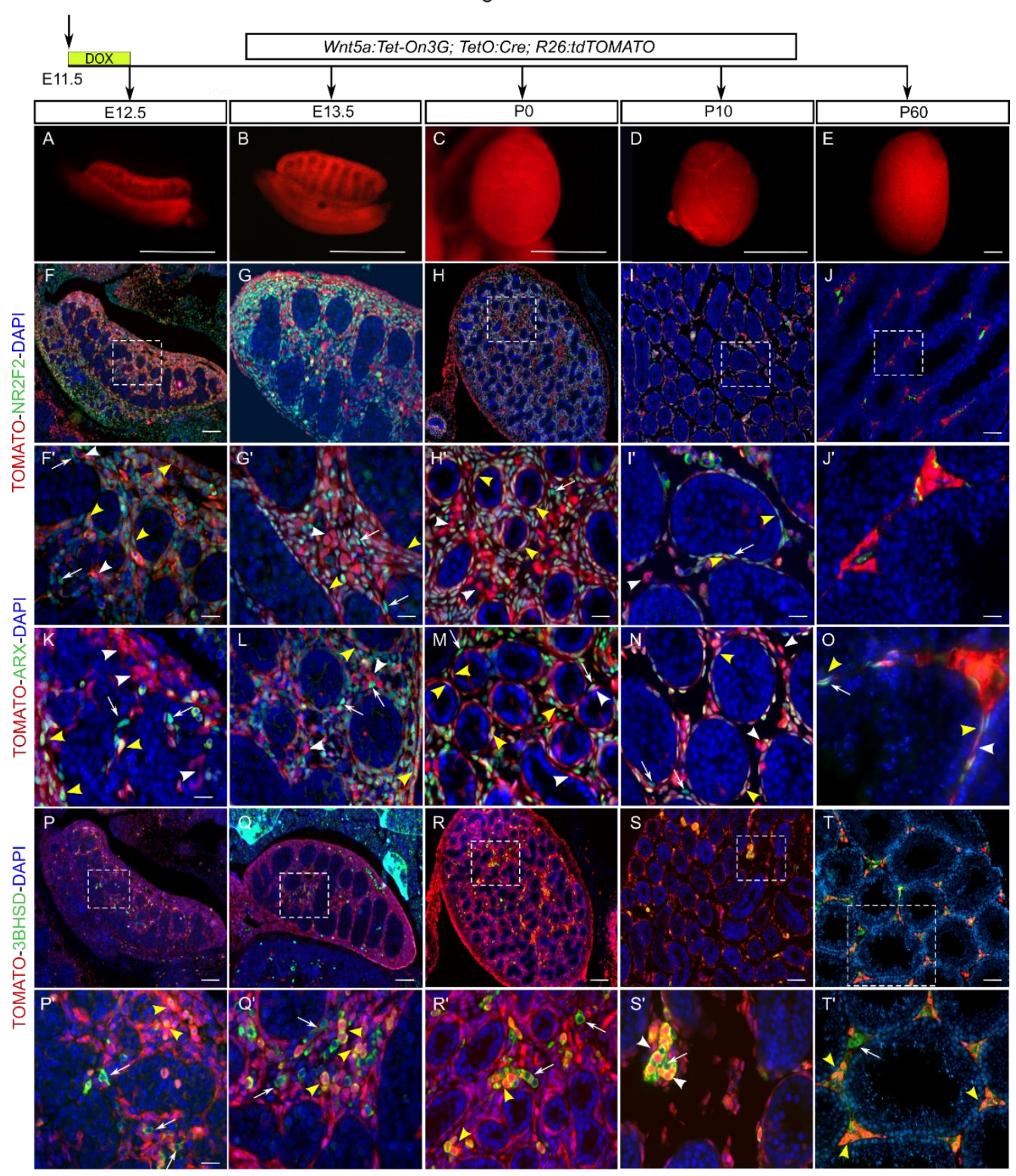

Figure 3: Lineage tracing of E11.5-E12.5 Wnt5a-expressing cells in developing and adult testes. (A-E) whole testis fluorescence of Wnt5a:Tet-On3G; TetO:Cre; R26:tdTOMATO animals dox-induced for $24 \mathrm{~h}$ at E11.5. Note the high level of fluorescence in the interstitial compartment of the developing testis and in the mesonephros. Immunofluorescence image of triple transgenic testes at E12.5 (F,F',K,P,P'), E13.5 (G,G',L,Q,Q'), P0 (H,H',M,R,R'), P10 (I,I',N,S,S') and P60 (J,J',O,T,T') exposed to dox 
between E11.5 and E12.5. Assessment of the identity of Tomato-labeled cells was obtained by double-immunofluorescence for Tomato and the progenitor markers NR2F2 (F-J and F'-J'), ARX (K-O) or the Leydig cell marker 3ßHSD (P-T, P'-T'). During testis development, a large fraction of interstitial cells are Tomato-labelled, many of them coexpressing the progenitor markers NR2F2 and ARX. In the adult testis, only a small subset of these Tomato-labelled cells still express the ARX progenitor marker, and are localized closed to the seminiferous tubules (yellow arrowhead in O). From E13.5 onwards, there is a rapid increase in Tomato positive cells which also express the Leydig cell marker 3ßHSD. At P10 and P60, the majority of the positive cells in 3BHSD are Tomato positive. Yellow arrowheads indicate co-expression, white arrowheads indicate Tomato expression, and white arrows indicate expression only in green channel. Nuclei were counterstained with 4',6-diamidino-2-phenylindole (DAPI). Scale bars: 1mm (A-E), $10 \mu \mathrm{m}$ (F'-O, P'-T') 20 $\mu \mathrm{m}(\mathrm{F}-\mathrm{G}, \mathrm{P}-\mathrm{Q})$, ), $50 \mu \mathrm{m}$ (I-J, S-T), $100 \mu \mathrm{m}$ (H-R). 
bioRxiv preprint doi: https://doi.org/10.1101/2020.07.25.221069; this version posted July 26, 2020. The copyright holder for this preprint (which was not certified by peer review) is the author/funder, who has granted bioRxiv a license to display the preprint in perpetuity. It is made available under aCC-BY-NC 4.0 International license.

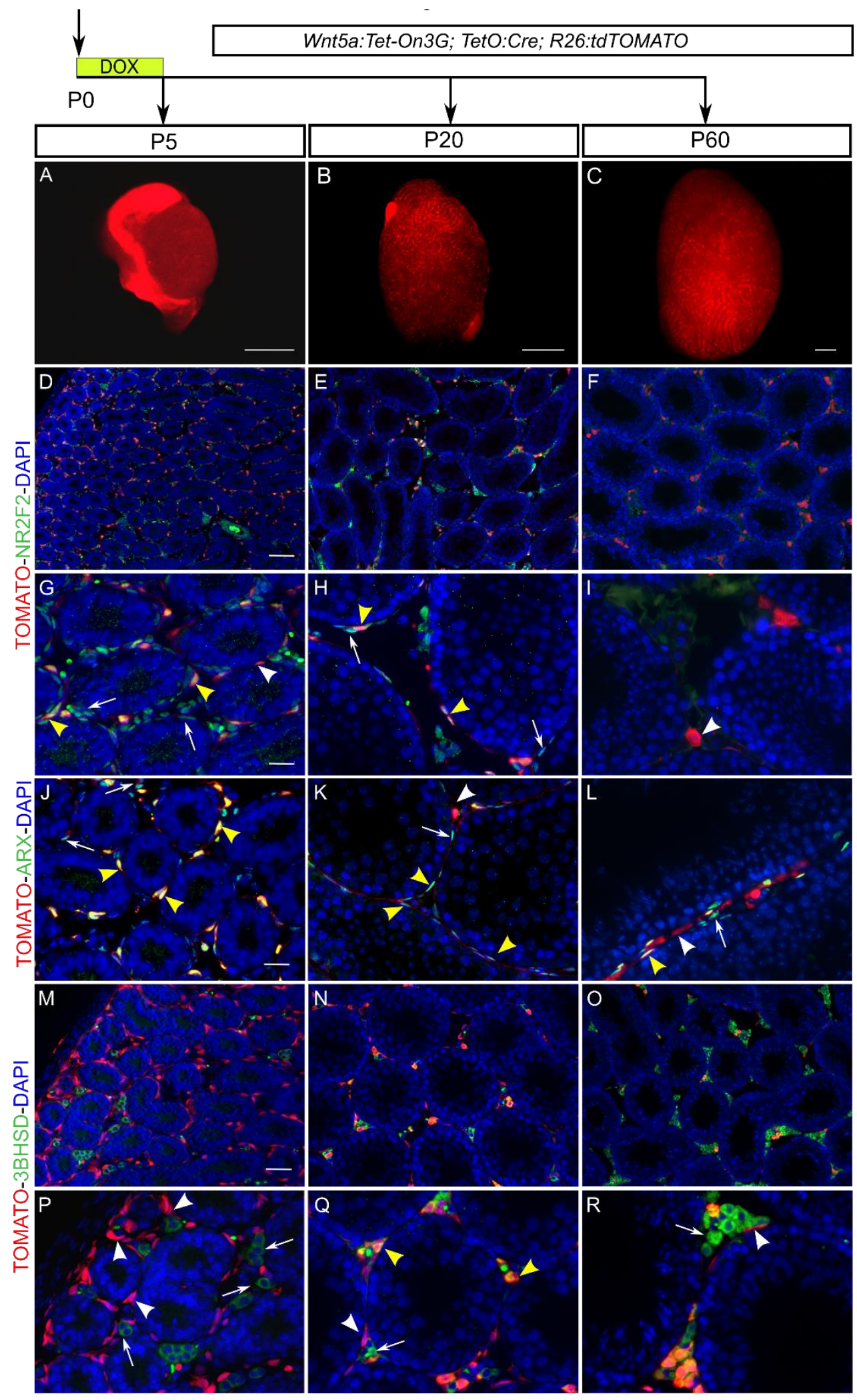


Figure 4: Lineage tracing of P0-P5 Wnt5a-expressing cells in developing and adult testes. (A-C) whole testis fluorescence of Wnt5a:Tet-On3G; TetO:Cre; R26:tdTOMATO animals dox-induced for 5 days at P0. Note the high level of fluorescence in the interstitial compartment of the developing testis. Immunofluorescence image of triple transgenic testes at P5 (D,G,J,M,P,S), P20 (E,H,K,N,Q,T) and P60 (F,I,L,O,R,U) exposed to dox between P0 and P5. Assessment of the identity of Tomato-labeled cells was obtained by double-immunofluorescence for Tomato and the progenitor markers NR2F2 (D-F and GI), ARX (J-L) and the Leydig cell marker 3ßHSD (M-O, P-R). At P5 and P20, most of Tomato-labelled cell co-express the progenitor markers NR2F2 and ARX. In the adult testis, only a small subset of these Tomato-labelled cells still express the ARX progenitor marker. At P5, the Leydig cells, as marked by 3ßHSD were mutually exclusive for Tomatolineage-traced Wnt5a expressing cells (M,P). By P20, a subset of Tomato-labeled cells expressed 3ßHSD (N,O,Q,R). Yellow arrowheads indicate co-expression, white arrowheads indicate Tomato expression, and white arrows indicate expression only in green channel. Nuclei were counterstained with 4',6-diamidino-2-phenylindole (DAPI). Scale bars: $1 \mathrm{~mm}$ (A-C), $50 \mu \mathrm{m}$ (D-F), $20 \mu \mathrm{m}$ (M-O), $10 \mu \mathrm{m}$ (G-L, P-R). 


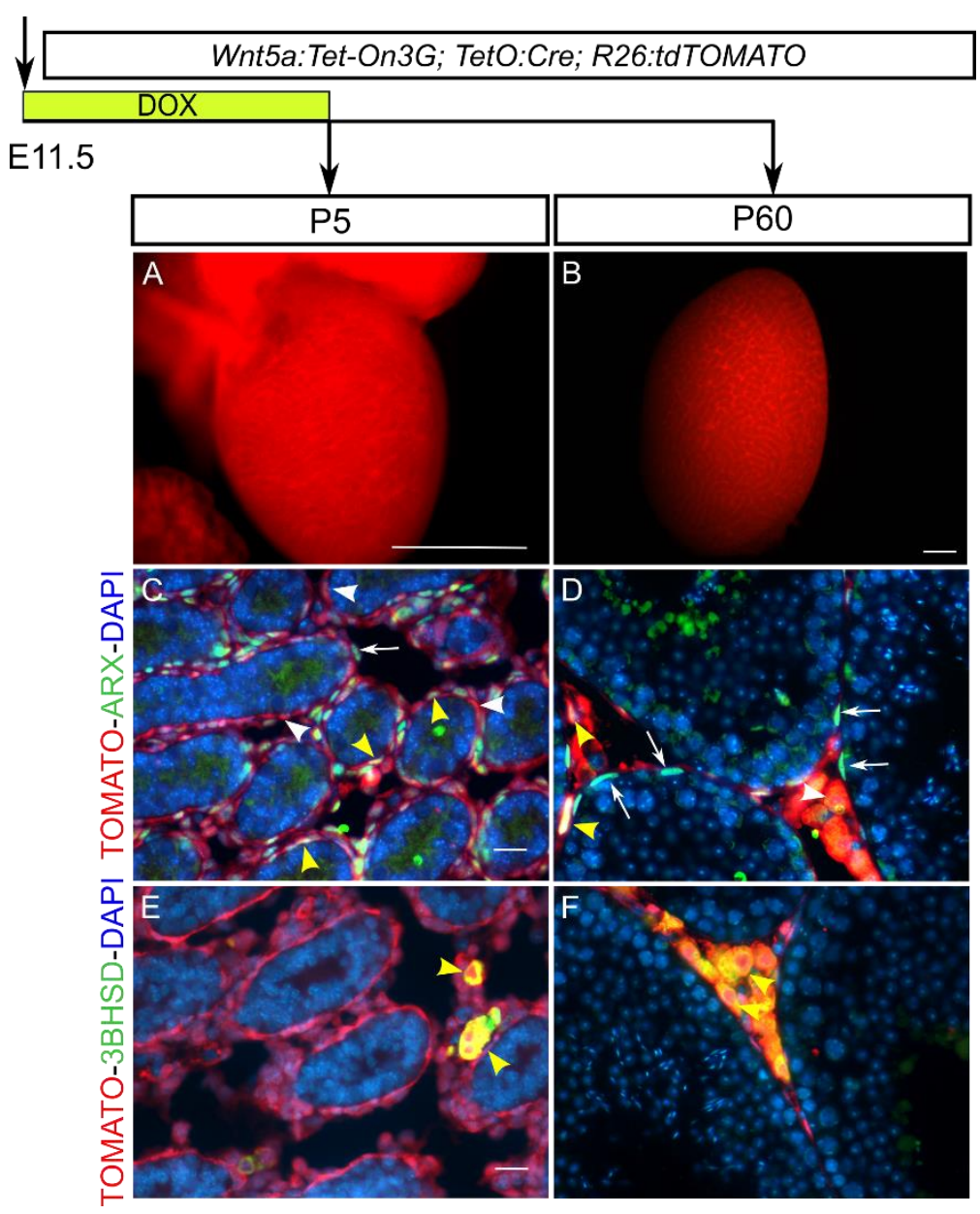

Figure 5: Lineage tracing of E11.5-P5 Wnt5a-expressing cells in post-natal and adult testes. (A-B) whole testis fluorescence of Wnt5a:Tet-On3G; TetO:Cre; R26:tdTOMATO animals dox-induced from E11.5 to P5. Note the high level of fluorescence in the interstitial compartment of the developing testis. Immunofluorescence image of triple transgenic testes at P5 (C,E,G) and P60 (D,F,H) exposed to dox between E11.5 and P5. Assessment of the identity of Tomato-labeled cells was obtained by double-immunofluorescence for Tomato and the progenitor marker ARX (C-D) and the Leydig cell marker $3 \beta \mathrm{HSD}(\mathrm{E}, \mathrm{F})$. Yellow arrowheads indicate co-expression, white arrowheads indicate TOMATO expression, and white arrows indicate expression only in green channel. Nuclei were counterstained with 4',6-diamidino-2-phenylindole (DAPI). Scale bars: 1mm (A-B), $10 \mu \mathrm{m}$ (C-F). 

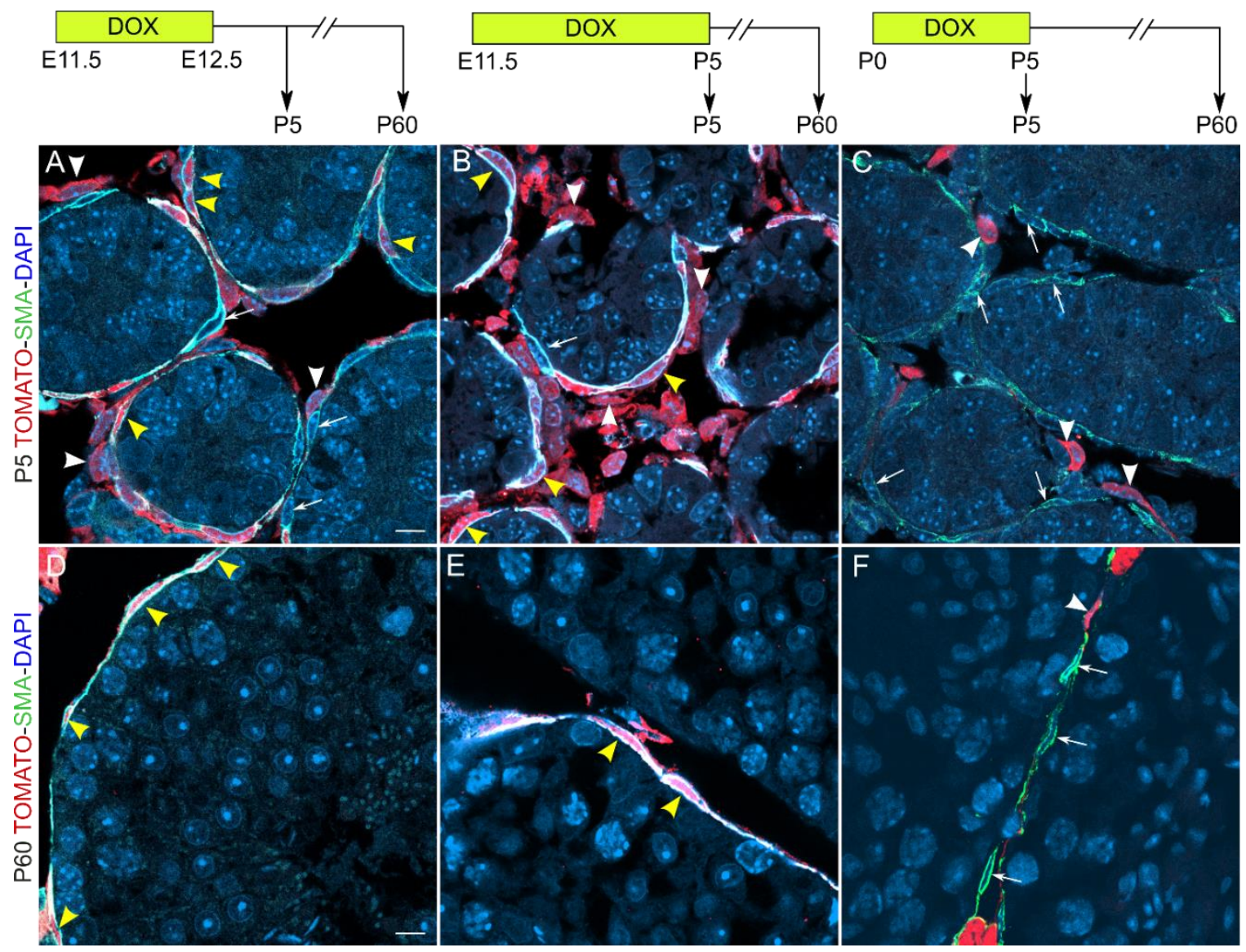

Figure 6: Co-immunofluorescence for tdTOMATO and ACTA2 in P5 and P60 testis induced by Dox at different developmental periods. Evaluation of Tomato-labelled cells and ACTA2 (SMA) expressing cells in P5 (A-C) and P60 (D-F) testes of Wnt5a:TetOn3G;TetO:Cre;R26:tdTOMATO mice induced with Dox at E11.5-E12.5 (A,D) or E11-5P5 (B,E) or P0-P5 (B,C,F). ACTA2-Tomato co-labelling is observed only with fetal inductions and is absent in perinatal induction (P0-P5). Yellow arrowheads indicate coexpression, white arrowheads indicate TOMATO expression. Scale bars: $10 \mu \mathrm{m}(\mathrm{A}, \mathrm{D})$. 

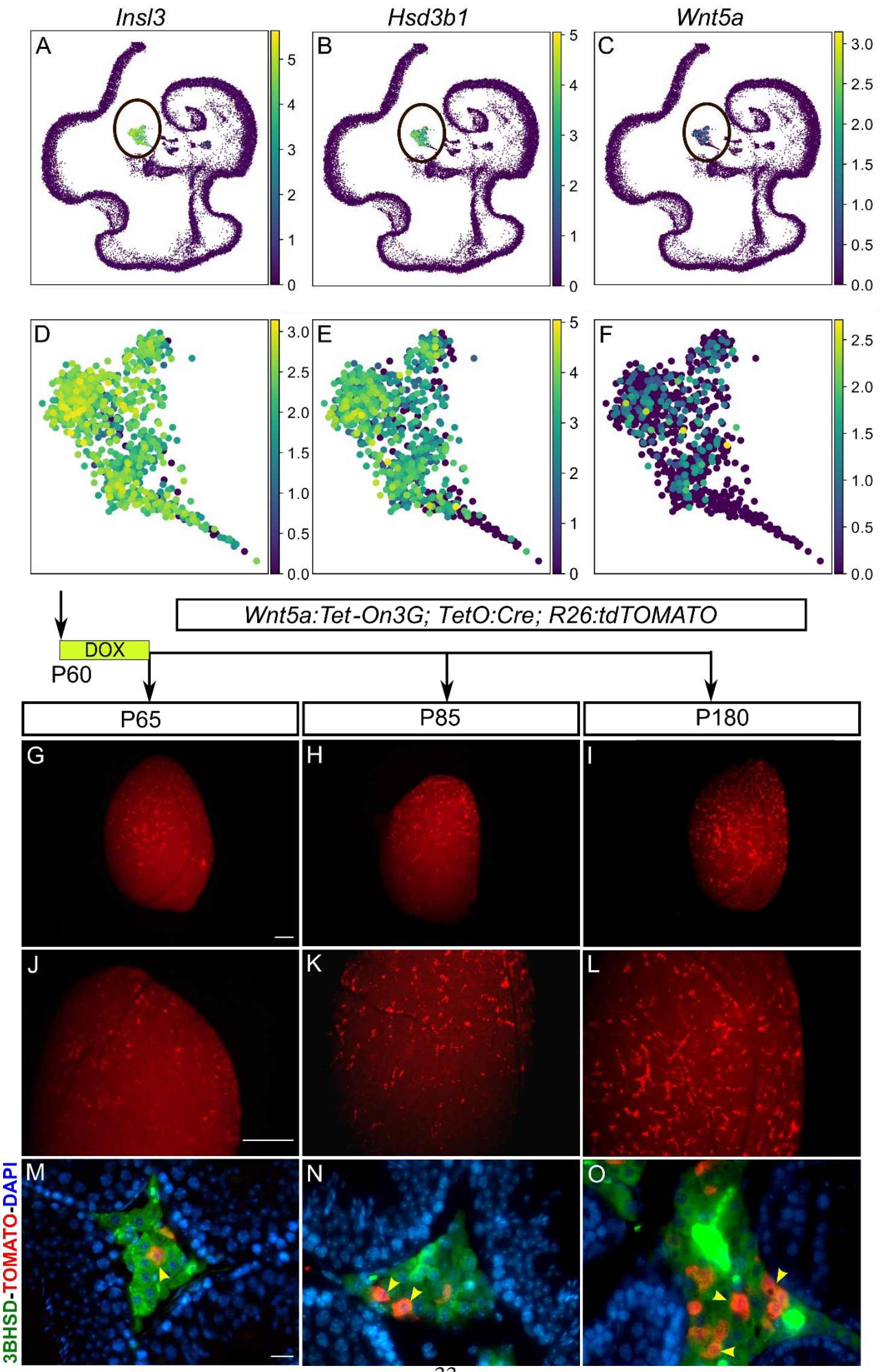
Figure 7: Wnt5a is expressed in a subpopulation of adult Leydig cells at P60 that increases in number over time. 10X scRNA-seq data of adult (age 8-10 weeks) mouse testes from Ernst et al. 2019 was processed (see methods) and LC cluster was identified with the expression of Insl3 and Hsd3bl (A-B). (C) Wnt5a expression profile in the whole P60 testes is restricted to the LC cluster. (D-F) Zoomed view of Insl3, hsd3 $\beta 1$, Wnt5a expression within LC cluster, where Wnt5a expressing cells are homogenously distributed in the group. (G-O) Lineage tracing of Wnt5a-derived LCs in Wnt5a:Tet-On3G; TetO:Cre; R26:tdTOMATO adults induced for 5 days from P60 to P65. (G-L) Whole testis fluorescence of triple transgenic animals dox-induced as observed at P65, P85 and P180. Note the rare initial fluorescent labelled cells scattered in the interstitial compartment of the testis at P60, whose number increase towards P180. Evaluation of the identity of Tomato-labeled cells at P65 (M), P85 (N) and P180 (O) by co-immunofluorescence for

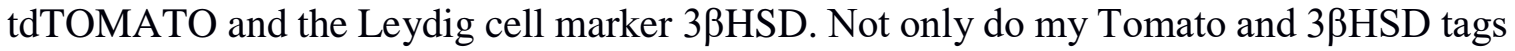
co-locate but the density of double positive cells increases with time suggesting clonal multiplication of ALCs. Yellow arrowheads indicate co-expression. Nuclei were counterstained with 4',6-diamidino-2-phenylindole (DAPI). Scale bars: 1mm (G-L), $10 \mu \mathrm{m}$ (M-O). 
bioRxiv preprint doi: https://doi.org/10.1101/2020.07.25.221069; this version posted July 26, 2020. The copyright holder for this preprint (which

was not certified by peer review) is the author/funder, who has granted bioRxiv a license to display the preprint in perpetuity. It is made available under aCC-BY-NC 4.0 International license.

\begin{tabular}{|c|c|c|c|c|c|c|c|c|c|}
\hline $\begin{array}{l}\text { Doxycycline } \\
\text { induction }\end{array}$ & $\begin{array}{l}\text { Analysis } \\
\text { Stage }\end{array}$ & $\begin{array}{l}\text { Biological } \\
\text { replicates }\end{array}$ & $\begin{array}{l}\text { Technical } \\
\text { replicates }\end{array}$ & $\begin{array}{l}\text { Total } \\
\text { Tom }^{+} \\
\text {cells }\end{array}$ & $\begin{array}{l}\text { Tom }{ }^{+} \\
\text {only } \\
\text { cells }\end{array}$ & $\begin{array}{l}\text { Total } \\
3 \mathrm{bHSD}^{+} \\
\text {cells }\end{array}$ & $\begin{array}{l}3 \mathrm{bHSD}^{+} \\
\text {only } \\
\text { cells }\end{array}$ & $\begin{array}{l}\text { Tom }^{+} ; 3 \mathrm{bHSD}^{+} \\
\text {cells }\end{array}$ & $\begin{array}{l}\text { Tom }^{+} ; 3 \mathrm{bHSD}^{+} / \text {total } \\
3 \mathrm{bHSD}{ }^{+} \text {cells }(\%)\end{array}$ \\
\hline \multirow[t]{2}{*}{ E11.5-P5 } & P5 & 3 & 5 & 17762 & 15937 & 2199 & 374 & 1825 & 83.0 \\
\hline & P60 & 4 & 14 & 161633 & 100784 & 67749 & 6900 & 60849 & 89.8 \\
\hline \multirow[t]{7}{*}{ E11.5-E12.5 } & E12.5 & 5 & 12 & 2771 & 2435 & 740 & 404 & 336 & 45.4 \\
\hline & E13.5 & 3 & 5 & 904 & 687 & 832 & 615 & 217 & 26.1 \\
\hline & P0 & 2 & 3 & 1545 & 1240 & 541 & 236 & 305 & 56.4 \\
\hline & P5 & 2 & 3 & 1013 & 904 & 297 & 188 & 109 & 36.7 \\
\hline & P10 & 1 & 2 & 11145 & 10450 & 794 & 99 & 695 & 87.5 \\
\hline & $\mathrm{P} 20$ & 1 & 3 & 8297 & 5413 & 4599 & 1715 & 2884 & 62.7 \\
\hline & P60 & 2 & 5 & 30277 & 19345 & 14842 & 3910 & 10932 & 73.7 \\
\hline \multirow[t]{3}{*}{ P0-P5 } & P5 & 2 & 4 & 3414 & 3371 & 2252 & 2209 & 43 & 1.9 \\
\hline & $\mathrm{P} 20$ & 1 & 8 & 3786 & 3731 & 1386 & 1331 & 55 & 4.0 \\
\hline & P60 & 4 & 8 & 11013 & 6974 & 23745 & 19706 & 4039 & 17.0 \\
\hline \multirow[t]{3}{*}{ P60-65 } & P65 & 3 & 15 & 641 & 43 & 114385 & 113787 & 598 & 0.5 \\
\hline & P85 & 4 & 14 & 1463 & 69 & 62698 & 61304 & 1394 & 2.2 \\
\hline & P180 & 3 & 12 & 5017 & 296 & 142031 & 137310 & 4721 & 3.3 \\
\hline
\end{tabular}

Table 1. Quantitative data from Tomato-3ßHSD double immunofluorescence analyses 


\section{Supplementary figure legends}

Figure S1: Absence of a testicular phenotype in XX and XY Wnt5a:Tet-On3G embryos at E13.5.

Figure S2: Characterization of the urogenital tract of XX and XY Wnt5a:Tet-On3G newborn pups.

Figure S3: Absence of a reproductive phenotype in XX and XY Wnt5a:Tet-On3G adult mice.

Figure S4: Co-immunofluorescence for tdTOMATO and the progenitor markers NESTIN in E12.5 and E13.5 testis.

Figure S5: Comparison between Wnt5a and $T c f 21$ expression in the developing testes.

Figure S6: Knock-in of the Tet-On $3 G$ transgene into the mouse Wnt5a locus.

Figure S7: CRISPR/Cas9 sgRNA design and cloning.

Figure S8: Knock-in of the Tet-On $3 G$ transgene into the murine Wnt5a locus.

Figure S9: Tet-ON $3 G$ site of insertion in the genome in F1. 